\title{
Proposed Breast Lump (FMTVDM/BEST) Pathway Nuclear Imaging Protocol
}

\author{
Richard M Fleming ${ }^{1 *}$, Matthew R Fleming ${ }^{1}$, Tapan K Chaudhuri ${ }^{2}$, Andrew McKusick ${ }^{1,3}$ and William C Dooley $^{4}$ \\ ${ }^{1}$ FHHI-Omnific Imaging-Camelot, USA
}

${ }^{2}$ Eastern Virginia Medical School, USA

${ }^{3}$ Sebec Consulting \& Media, North Carolina

${ }^{4}$ Oklahoma University Health Science Center, USA

*Corresponding author: Richard M Fleming, FHHI-Omnific Imaging-Camelot, El Segundo, CA, USA.

Received Date: June 24, 2019

Published Date: June 28, 2019

Keywords: FMTVDM; Breast lump; Breast cancer; Breast inflammation; Transitional breast changes; Breast treatment; Primary and secondary breast cancer

\section{Explanation}

One of the major problems associated with the "screening" of women and men for breast cancer is the utilization of several "qualitative" imaging studies associated with sensitivity and specificity problems. According to the National Cancer Institute (NCI), 10\% of all women who don't have breast cancer are told they have breast cancer based upon the results of a "screening" mammogram. The odds of a woman being told she has breast cancer increases to 50-50 if she has a mammogram 10-years in a row. Problems with sensitivity are seen most frequently in younger women and women with "dense" breasts, which has resulted in national legislation in the USA requiring that mammography reports include a disclaimer telling women that if they have dense breast tissue, something seen in half of all women, they may have a breast cancer which was missed by mammography. The cumulative effect of these sensitivity and specificity errors are associated with $6-46 \%$ of all women with breast cancer being missed using mammography. A 25-year Canadian Breast Cancer Screening Study revealed "no survival benefit" from screening mammography [1] (Figure 1).

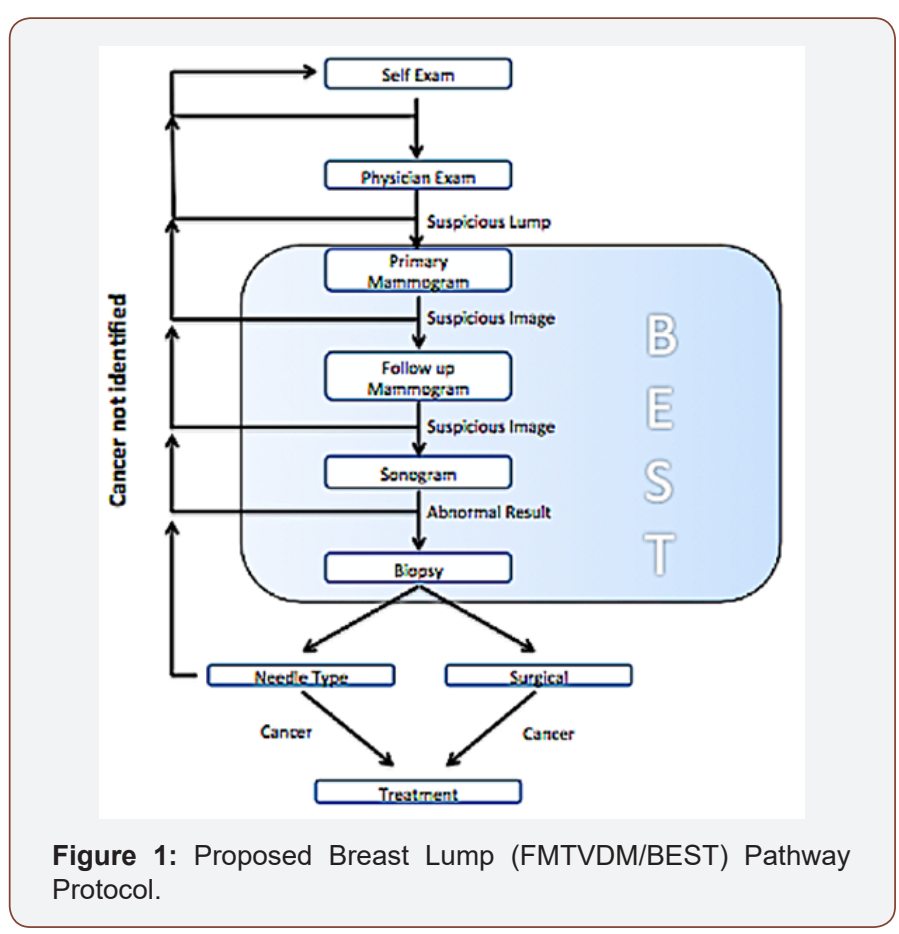


As shown in Figure 1, women and men who are confronted with the concern of breast cancer go through a several step processes including physical exam, both by themselves and their physician(s), followed by mammography including both screening and potentially further mammography either initially or over consecutive years. Mammography however is frequently used in conjunction with ultrasound, which is looking for the presence or absence of fluid. The more "solid" the appearance, the "more likely" a cancer is present; however, this too is not always the case and approximately $10 \%$ of all solid masses are non-cancerous, while an additional $10 \%$ of those masses which are cystic or fluid filled turn out to be cancerous. In the end, this frequently results in tissue sampling either closed or open to make the final diagnosis. All of these steps take time before any treatment can occur. In addition to the lost time, there are cost considerations including lost earnings and the associated personal stress and related consequences (Figure 2).

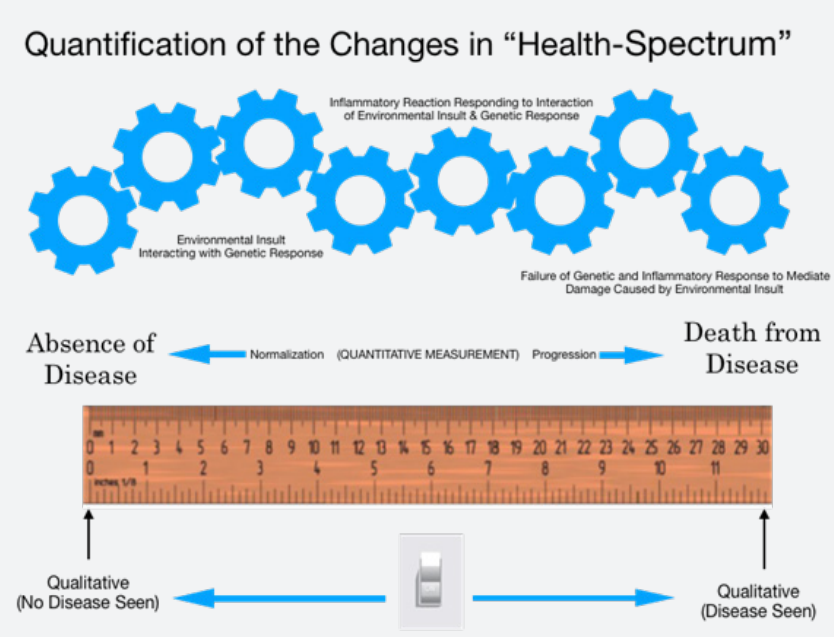

Figure 2: Quantification of the "Health-Spectrum" for Cancer.

Unfortunately, an all too often problem is the failure to recognize that diseases like coronary artery disease, high blood pressure, diabetes and cancer are not actually diseases which are either yes or no outcomes. The process of developing cancer is not a sudden light switch change in body biology but rather the result of a series of changes that occur over time as the genetic material of a person interacts with the environment the cells find themselves it. As such, the process is transitional as shown in Figure 2 and merely looking for a yes/no answer consequently leads to erroneous outcomes. This proposed "Breast Lump Pathway Protocol" proposes a NEW approach to addressing breast cancer; one, which takes this "transitionally" changing process into consideration. To be able to consider this approach requires the development of a method, which can "quantitatively" measure these transitional changes in tissue.

FMTVDM is the only patented method [2-5], which initially calibrates the nuclear cameras (SPECT and PET) used for a variety of medical problems and then diagnostically measures changes in tissue after enhancing both the delivery and uptake of isotopes based upon regional blood flow and metabolic differences. As such FMTVDM not only finds the presence and absence of cancer but it can "measure" (quantify) these transitional states. The consequence of being able to "measure" these transitional changes, provides an accurate, consistent and reproducible method to monitor change over time, including treatment effects [6-8] in both men [9] and women, women with dense breasts [10] and the ability to find and measure secondary cancers being suppressed by primary cancers
[11], alerting clinicians to the presence of the secondary cancer and the need for treatment directed at the secondary cancer, sooner than later. We propose the use of the Breast Lump Pathway Protocol and its comparison with the alternative multi step approach currently being used in the evaluation and treatment recommendations currently employed.

\section{Acknowledgement}

None.

\section{Conflict of Interest}

FMTVDM patent was issued to primary author. All figures reproduced by expressed consent of primary author.

\section{References}

1. Miller AB, Wall C, Baines CJ, et al. Twenty-five-year follow-up for breast cancer incidence and mortality of the Canadian National Breast Screening Study: randomized screening trial. BMJ 11(348): g366.

2. Fleming RM (2017) The Fleming Method for Tissue and Vascular Differentiation and Metabolism (FMTVDM) using same state single or sequential quantification comparisons.

3. Fleming RM, Dooley WC, Chaudhuri TK (2017) The Development of FMTVDM-BEST IMAGING@(D): The Answer for Breast Cancer. Breast Enhanced Scintigraphy Test (BEST(C)(D): Quantifying the Detection of Breast Cancer and its Treatment. J Nucl Med Radiat Ther 8(6): 350.

4. Fleming RM, Fleming MR, Dooley WC, McKusick A. FMTVDM-BESTC(P Breast Cancer Imaging eliminates the fear of having BRCA1 and BRCA2 Breast Cancer Genes. J Clin Mol Med 1(2):1-2.

5. Fleming RM, Fleming MR, McKusick A, Chaudhuri TK (2018) Semiquantification limitations: FMTVDM(C) (P demonstrates quantified tumor response to treatment with both regional blood flow and metabolic changes. J Nucl Med 59(10):1643-1644. 
6. Fleming RM, Fleming MR, Chaudhuri TK, Dooley WC, McKusick A (2018) FMTVDM; B.E.S.T.C(P) Imaging Theranostically Used to Guide Treatment Response in a woman With Recalcitrant Breast Cancer. Biomed J Sci \& Tech Res.

7. Fleming RM, Fleming MR, Chaudhuri TK, Dooley WC. Theranostic Information Provided by FMTVDM(C); B.E.S.T. (C) (P Imaging. Adv Hema Onco Res 2(1): 1-3.

8. Fleming RM, Fleming MR, Chaudhuri TK, Dooley WC, McKusick A (2019) FMTVDM-BEST (B.E.S.T.) Breast Cancer Imaging Test (BBCIT): An Enhanced Quantitative Method for Performing Molecular Breast Imaging (MBI). Annals of Biomedical Imaging 11: 1001.
9. Fleming RM, Fleming MR, Chaudhuri TK, Dooley WC, McKusick A (2019) FMTVDM/BEST Imaging Equally Applicable for Male Breast Cancer. Int J Women's Health Wellness 5(2): 093.

10. Fleming RM, Fleming MR, Chaudhuri TK, Dooley WC, McKusick A (2019) FMTVDM/BEST Imaging for Women with Breast Implants and Dense Breasts. Int J Women's Health Wellness 5(2): 092.

11. Fleming RM, Fleming MR, Chaudhuri TK, Dooley WC, McKusick A (2019) Unmasking Hidden Recurrent Cancers using FMTVDM/BEST. The Fleming Cancer Hypothesis. Int J Women's Health Wellness 5(2): 094. 